\title{
CLINICAL VALUE OF RECTAL THIOPENTONE IN PAEDIATRIC ANAESTHESIA *
}

\author{
Henri Drolet, M D , And Mrchel Boisvert, m d †
}

IT BEHOOVES every physician to consider thoughtfully the emotional trauma to which a child is subjected by a sudden admission to hospital Such an experience is inevitably associated with insecurity and with suffering

For those of us who spend our days in the operating room it is too easy to consider the child as if he were a miniatue adult and to treat him as such In fact, nothing could be further from the truth A child is an emotional and not a rational being Admission to hospital brings with it a series of new and distressing experiences separation from parents, the unknown of the operating room, the instruments, the lights and strange people with masks-all present an aspect which is far from reassuring All of this is merely the prelude to the unnerving moment which the child must face entirely alone-the induction of anaesthesia

Psychiatrists have underlined the psychic sequelae that can result from an anaesthetic in which the emotional reaction of the child has been overlooked Numerous emotional and behavioural problems have been attributed to our present methods of anaesthesia in children ${ }^{1-3}$ Apart from eventual psychic repercussions, the intense fear of a child who is brought to the operating room still partly awake and, in spite of his cries and protestations, is held down by force and made to breathe objectionable vapours would seem to us a nightmare spectacle had not custom dulled the edge of our perception

In the conduct of an anaesthetic, premedication and the skill of the anaesthetist who wins the child's confidence are most important Also of value are the preoperative meeting with the child and parents, the presence in the operating room of a nurse known to the patient, and even the transportation to the operating room in his own bed While we believe in the merit of such a friendly and persuasive approach, we must admit that this psychological preparation is difficult, often inadequate, and sometimes impossible Therefore, many failules will occur This feeling of sympathy which has been engendered on the day before the operation will too often disappear very quickly when the child is taken away from his mother and, despite a diplomatic approach, a restraining method will often have to be employed

Pre-anaesthetic hypnosis obviates the use of these methods Administered in the wards, it saves the child the shock of separation, the worries of the operating room, and also the terrors of induction of anaesthesia Thiopentone aroused our interest for the following reasons

1 The cortical and hypothalamic action of barbiturates helps decrease the preoperative anxiety and lowers the arritibility level of the anxious patient

-Presented at the Annual Meehng, Canadian Andesthetists' Society, May 10-14, 1964

†Hôpital St-Ambroise, Loretteville, Québec 


\section{Thiopentone has a euphoric and amnesic effect}

Unfortunately, until 1959, administration of rectal thiopentone caused as many problems as were solved Following the early work of Albert, ${ }^{4}$ rectal thiopentone was offered as a suspension This aroused our interest because of its many advantages over aqueous solution and suppositories The technical drawbacks of utilizing rectal thiopentone as a basic agent of narcosis were in fact eliminated with this suspension

The new suspension is offered in disposable calibrated plastic syringes with removable rectal tips It is easy to administer and always ready for use Absorption is slower and more uniform than with the solution, and enemas are not necessary It is stored at room temperature and stability is remarl.able Since its introduction, we have used this suspension in more than 2,000 cases and have been impressed with its efficacy and safety No death or any important morbidity was encountered We believed that a closer look at our results would be of interest, and thus we have studied the effects of rectal thiopentone on the main vital functions in our last 300 cases

\section{AGE AND WEIGHT}

This series consists of an unselected group of 300 children of both sexes, ranging in age from 6 months to 7 years (mean 3 years, 4 months) and with an average weight of $32 \mathrm{lb}$ It would appear that before the age of 18 months, most child en do not remember their stay in the hospital, ${ }^{5}$ but Schaffer and Callender ${ }^{6}$ mention 7 months and over as being critical in this respect $\mathbb{B}$ lum ${ }^{7}$ states that hospitalization is a brutal event for any child up to 5 years of age The general concensus seems to be that after 6 years of age children ane capable of reasoning and are less likely to be disturbed

\section{Nature and Duration of Procedures}

More than 85 per cent of the procedures were operations on tne tnroat, nose, larynx, etc, such as tonsillectomies, adenordectomies, myringotomies, and exploration of lacrimal ducts General surgery made up the rest of the procedures, such as herniorrhaphies, skin grafts, plastic surgery, and various abdominal procedui es We also used rectal thiopentone for certain radiological procedures in uncooperative children mastoid, smus, and certain skull X-rays, and for urography

The average duration of procedures was 22 minutes with a range of 5 to 90 minutes

\section{Premedication}

Premedication consisted of mependine and atropine in a dosage calculated according to the age of the child ${ }^{*}$ Dosage also varied according to the physical state and weight of the patient At the begmning, prernedication was administered

"Atropine 6 months to 1 year, $1 / 400 \mathrm{gr}, 1$ year to 6 year's, $1 / 300 \mathrm{gr}, 6$ years to 15 years, $1 / 200 \mathrm{gr}$

Mependine $5 \mathrm{mg}$ per year of age up to 10 years, $50 \mathrm{mg}$ from 10 years to 14 years

With a temperature of over $102^{\circ} \mathrm{F}$ and age under 6 months, consult the anaesthetust 
before thiopentone This was contrary to the goal we were aimmng at because children have a natural aversion to injections Therefore, we decided to wait until rectal thiopentone had shown its effect before giving the injection This unorthodox approach appeared to be justified when if was found that hypersalivation and cardiac vagotonia in fact did not occur

Rectal thiopentone suspension is prepared with 40 per cent of sodium carbonate as a buffer and mineral oil (Abbott laboratories) It is supplied in a disposable plastic syringe with detachable rectal tips, also of plastic Each syringe is graduated in increments of $100 \mathrm{mg}$ The plunger carries a rotating locking disk, thus allowing predetermination of the dose to be given This prevents inadvertent overdosage We have not encountered any problems wath the syringe or the suspension

Doubtless because of the small volume of the suspension which is administered, we have encountered only three cases of defaecation in our group of 300 patients

We suggest that the thropentone be administered by nurses who are well accepted by children In our 300 cases, the nurse in charge of paediatrics and a few nurses working in operating rooms administered the drug Onlly 10 per cent of the children resented the procedure Lubrication of the rectal tip is important for administration

\section{Rectal Thropen frone Dosage}

We tried various doses before reaching the optimum for our goal We quickly abandoned the $20 \mathrm{mg} / \mathrm{lb}$ dose, which we had seen suggested, 8 because of respiratory trouble and prolonged sleep Wath $10 \mathrm{mg} / \mathrm{lb}, 43$ per cent of the patients were sleeping and 36 per cent were placid With the intent of acheving greater effect without danger to the chuldren, we decided on a dosage of 13 $\mathrm{mg} / \mathrm{lb}$ We have been using this dose for nearly a year now

\section{LATENT PERTOD}

The onset of action of the rectal thiopentone suspension occurred after an average of $7 \%$ minutes, varying from 5 to 16 minutes

\section{EFFICACY}

Our young patients were divided into four groups according to the effect of rectal thiopentone

1 In the first group were children who were asleep when they entered the operating room and did not wake up during induction of anaesthesia

2 In the second group were children who were in a state of indifference to their surroundings when they entered the operating room Also included in this group were children who were awakened by the induction of anaesthesia but did not show any agitation Experience has shown that these children did not remember their stay in the operating room

3 A third group included the children who showed some anxiety and who protested very mildly to the administration of anaesthetic agents

4 A. fourth group included the well-known child who, being afraid, is agitated and fills the operating room with his shouts 
The following are the results by group with a dosage of $13 \mathrm{mg} / \mathrm{lb}$..

$\begin{array}{llr}\text { 1st group } & \text { Sleep or hypnosis } & 77 \%-231 \text { cases } \\ \text { 2nd group } & \text { Placidity } & 15 \%-45 \text { cases } \\ \text { 3rd group } & \text { Mild resentment } & 7 \%-21 \text { cases } \\ \text { 4th group } & \text { Strong resentment } & 1 \%-3 \text { cases }\end{array}$

These figures show that 92 per cent of our patients did not remember their stay in the operating room, the first group because they slept, the second group because of the amnesic action of thiopentone We have not tried to obtain a higher percentage than 92 pei cent, experience having shown us that higher doses carry risks of respiratory depression and obstruction All patients who received rectal thıopentone were kept in a special location under the supervision of a competent nurse just as if they were in the recovery room

\section{Respiratory Modification}

The rusk of significant respiratory depression is negligible at the dosage of thiopentone which we have used The respiratory disturbances which we observed were due to the combined use of thiopentone and premedication We did not wish to deprive our patients of the safety provided by atropine for the sake of an experiment For the same reason we continued to use meperidine to control postoperative agitation

We first studied the respiratory rate before the administration of rectal thiopentone The average was 32 respirations per minute Upon the arrival of the children in the operating room, a deciease of 4 respirations per minute or 125 per cent was observed We then studied the tidal air volume As it is most difficult to obtain a satisfactory reading in a young child, we referred to Radford's nomogram for the iespiratory values before the administration of the thiopentone As imprecise as it is, this nomogram is still useful until other standards become generally accepted After administration of rectal thiopentone, we measured the tidal air in every case where it was possible, both in sleeping patients and in the majority of those who were resting quietly The apparatus used for this study was a mask with minimal dead space (Renbaker mask) which was directly connected to the Wright respirometer We paid particular attention to obtaining a leak-proof adjustment of the mask on the child's face The average tidal aur obtained by this method was $102 \mathrm{ml}$ as compared with $105 \mathrm{ml}$ established from Radford's nomogram Thus difference is not sngnuficant

Because of the decrease of respuratory rale, ventilation is dimunished Clinically, this decrease of ventilation did not concern us In fact, the slowing of basal metabolssm, the good colour of the patient, the sum total of the defence mecha. misms of the body, and the assistance to the respiration which we provided throughout the anaesthesia appeared to obviate any type of respiratory disturbance

\section{Circulatoriy Chinges}

Next, we proceeded to the study of certain effects of rectal thiopentone on circulation We observed an average increase of the pulse rate of 24 beats per 
minute in 95 per cent of the cases In the other 5 per cent, no change was noted This tachycardia was probably caused by the atropine Blood pressure did not show any significant change

\section{Duration of ACtion}

Before considering this aspect of our study, it is desirable to say a word on the maintenance of anaesthesia It has a considerable effect on the duration of action of any preoperative drug

Injection of succinylcholine for intubation enables one to avoid too deep a level of anaesthesia A mixture of halothane-ether of 45 per cent given for 3 to 4 minutes is sufficient for induction This having been said, let us now look at the maintenance of anaesthesia As an example, let us consider a tonsillectomy lasting 20 minutes Normally, we use a concentration of azeotropic mixture of halothane and ether between 15 and 25 per cent for 15 minutes so as to limit the gas flow to 4 litres of nitrous oxide and 2 litres of oxygen durnng the last 5 minutes Nitrous oxide was always combined with oxygen durng anaesthesia during the study With this method, bucking is exceptional and extubation does not cause spasm of the respiratory tree

As no child was brought back to the ward before consciousness was restored, the time spent in the iecovery room was taken as an empincal measure for the evaluation of the length of action of rectal thiopentone It is understood that no child who was showing agitation was taken out of the recovery room before he had calmed down Within these limits we have established that the time spent by our patients in the recovery room was from 15 to 75 minutes, the average time being 325 minutes The duration of action of rectal thiopentone 15 , , for the most part, related first to the dosage and then to the particular metabolism of each individual It is also evident that time relationships between the administration of thiopentone and the moment of the beginning of anaesthesia, on the one hand, and the duration of anaesthesia, on the other, are important factors

\section{EFFECIS UPON RECTAL Mucosa}

We attempted to explore the theoretical possibility of irritation of the human rectal mucosa by the thiopentone suspension In practice we had never encountered any such adverse effect Nevertheless, a series of proctoscopies were performed 24 and 48 hours after the admimistration of the suspension More than 20 proctoscopies already performed have shown a perfectly normal and healthy rectal mucosa

\section{COMPLica TIONS}

The side-effects encountered an our young patients have been

1 Four cases of laryngeal spasm of mild degree These patients responded well to the administration of oxygen under pressure

2 Three cases of salivation of average intensity This was probably due to the fact that the atropine had not yet attained its maximum effect 
3 Ten cases of vomiting of red blood or dark blood three in the recovery rodm and seven in the ward

4 Thirty-five cases of agitation in the recovery room, or 117 per cent of all cases These patients immediately received promazine $5 \mathrm{mg} /$ year of age up to $25 \mathrm{mg}$ Fifteen to 20 minutes later, these children were usually calm In our view such distressing agitation should not be permitted to continue

With regard to these complications, it seems to us that the side-effects which occurred in our young patients compare favourably in frequency and seriousness with those usually found with any anaesthesıa for otorhinolaryngology

\section{Contraindications}

As the contraindications to the use of rectal thiopentone suspension are the same as those for intravenous thiopentone and also because they are seldom encountered in children, we simply refer to the classic monograph of Dundee ${ }^{9}$ To be more specific, we should like to point out that the suspension is not recommended in operations on the rectum and inflammatory or neoplastic lesions of the lower intestine

\section{Conclusion}

We have described a method of basal narcosis in paediatric anaesthesia using a rectal thopentone suspension Rectal thiopentone has been unpopular because of problems encountered with the older forms of preparation such as the solution and suppositories Rectal thiopentone in suspension form is a much improved product We have found it to be a very humane form of anaesthesia for children The techmique is now very simple and should present no difficulty Moreover, rectal thiopentone suspension prevents all psychological trauma to the young child and provides as well a high degree of safety Parents are grateful for being spared the pitiful scenes of separation Surgeons no longer have to witness behavioural problems associated with anaesthesia

The evidence supporting these statements is conclusive and extensive The observations of physiological function which we have carried out have confirmed our clinical impressions of the efficacy and safety of the drug Certainly, additional observations such as oximetry, $p \mathrm{CO}_{2}, p \mathrm{O}_{2}$, and precise measurements of the effects of rectal thiopentone on cardiac and pulmonary function would be of great interest Nevertheless, our lack of the necessary equipment and laboratory facilities does not diminish the value of clinical observation In the final analysis it is the clinical picture which will eventually decide what is best for the patient By these criteria rectal thiopentone suspension has certanly proved itself

\section{RÉSUMÉ}

Les auteurs présentent leur technique de narcose de base avec la suspension de thropentone rectal en anesthésie pédiatrique Leur série est formée de 300 cas consécutifs non sélectionnés

Sont successivement analysés l'âge et le poids des enfants, la nature et la durée des interventions chirurgicales auxquelles ils ont été soumis, la dose de 
thiopentone rectal utılisé, le temps requis pour obtenur l'hypnose, l'efficacité hypnotique du produit, sa durée d'action et les complications survenues au cours de la série

Sont ensuite évalués clinıquement les retentıssements du thıpentone rectal sur les principales fonctions ventilatorres et curculatorres, de même que sur la muqueuse rectale

Les auteurs concluent que la suspension de thiopentone rectal, telle qu'lls l'ont utilisée, permet d'éviter les traumatısmes psychologıques fréquemment causés chez les enfants par les méthodes courantes d'anesthésie De plus, cette méthode de narcose de base s'est avérée, entre leur, mains, à la fors simple et de toute sécurté

\section{ACKNOWLEDGMEN TS}

This study was supported by a grant of the Medical Department, Abbott Laboratories Limited, which also made available supplies of the rectal suspension of Pentothal ${ }^{\text {B }}$

\section{REFERENCES}

1 Eckenhorf, J D Preanesthetic Sedation of Children Analysis of the Effects for Tonsillectomy and Adenordectomy A M Arch Otolaryngol 57 441 (1953)

2 Jackson, $K$, Winkiex, $\mathbb{R}$, Faust, $O A, \&$ Cermack, $\mathbb{E}$ G Problems of Emotional Trauma in Hospital Ireatment of Children J.A M A 1491536 (1952)

3 Levy, D M Psychic Trauma of Operations in Children and Note on Combat Neurosis Am J Dis Child 697 (1945)

4 Albert, $S$ N et al Rectal Thiopental in New Dosage Forms Multıdose suppositories or Suspension Abbosert Anesth \& Analg 3856 (1959)

5 Wylte, W D \& Churchill-Davmson, H C A Practice of Anaesthesia, $p$, 883 (Chicago Year Book Pub, Inc, 1960)

6 Schaffer, $\mathrm{H} \mathbb{R}$ \& Callender, W M Psychologic Effects of Hospitalizailion in Infancy Pediatncs 24528 (1959)

7 Brom, G E Reactions of Hospitalized Children to Illness Pediatrics 22590 (1958)

8 Abbott Laboratories Physician's Guide to Clinical Use of Pentothal Sodium, p 23 (1960)

9 Dundez, J W Thiopentone and Other Thioburbiturates London E \& S Livingstone Ltd (1956) 